\title{
Bibliotherapy: A Framework for Understanding Pre-Service Primary Teachers' Affective Responses to Learning and Teaching Mathematics
}

\author{
Sue Wilson \\ Australian Catholic University \\ <sue.wilson@acu.edu.au> \\ Steve Thornton \\ Charles Darwin University
}

\begin{abstract}
This paper advocates bibliotherapy as a powerful tool through which teacher educators can analyze and interpret the affective responses of pre-service primary teachers. Pre-service teachers analyzed readings about school students' learning, and reflected on and reconstructed their understanding of their own school experiences. This process facilitated a meta-affective change that enabled the pre-service teachers to reconsider their assessment of their capacity to learn and understand mathematics. We describe this change using the stages of bibliotherapy. This change enabled the pre-service teachers to approach their future teaching of mathematics with greater enthusiasm, and empowered them to construct positive projective identities.
\end{abstract}

Keywords: Affect, meta-affect, bibliotherapy, pre-service mathematics teacher education, projective identity, reflection

People will forget what you said. People will forget what you did. But people will never forget how you made them feel (Unknown).

\section{Introduction}

Mathematics anxiety has been a focus of concern among educators in many countries for many years. Pre-service primary (elementary) teachers' mathematics anxiety affects the way they engage with mathematics and the way they teach. Furner and GonzalezDeHassstate that "teachers can play an active role in both helping to prevent and reduce mathematics anxiety in their students” (2011, p. 237). Hence it is important to address mathematics anxiety during teacher education courses.

Bibliotherapy, developed in psychology and library science aims to assist individuals to overcome negative emotions related to a real-life problem by guided reading followed by individual or group discussion in a non-threatening environment (Hendricks, Hendricks \& Cochran, 1999). In this paper we describe how the stages of bibliotherapy were used to analyze the reflective responses of primary pre-service teachers during a course focusing on school students' mathematics learning difficulties.

In comparison to other reflective practices, the potential of bibliotherapy lies in the opportunity for the process to simultaneously promote a cognitive and emotional response (Morawski \& Gilbert, 2000). This is particularly important in the context of mathematics teacher education where negative feelings a bout mathematics have been shown to be 
notoriously hard to reverse and where the interaction between knowledge and emotions has a powerful influence on pre-service teachers' perceptions of teaching (Pajares, 1992). We propose that understanding the stages of bibliotherapy-identification, catharsis, insight and universalization-will better enable teacher educators to address simultaneously the cognitive and affective domains, and to develop meta-affective capabilities that enable pre-service teachers to manage their emotional responses in productive ways (DeBellis \& Goldin, 1997).

\section{The Genesis of Our Research}

During a course focusing on mathematics and learning difficulties, we observed that thinking about the emotional and cognitive problems of school students caused pre-service teachers to reflect more deeply on their own experiences of mathematics. Their written reflections revealed that, when examining case studies of children who found learning mathematics difficult, pre-service teachers strongly identified with such children. An unexpected outcome of the unit was that many expressed greater confidence in their own ability to learn and teach mathematics. Hence our initial research question was: Might an explicit focus on children's learning/learned difficulties impact upon pre-service teachers' confidence as future teachers of primary school mathematics?

We set up a small-scale research project to investigate this question with the following year's group of pre-service teachers. Readings were selected that we thought might encourage these pre-service teachers to re-evaluate their own experiences, develop a more positive self-image as learners of mathematics and gain insight into how children's anxiety about mathematics can be minimized by teachers. We were surprised that, when responding to the readings, the pre-service teachers often put themselves in the place of the child. They provided graphic descriptions of incidents in their own schooling, being able to identify precisely when "their love of maths changed" (Wilson \& Thornton, 2005). They identified with the school students in the readings, releasing pent-up emotion and gaining insight into the causes of their feelings of inadequacy as mathematicians. They realized that they were "not alone in this anxiety", and were "healed and enthused" as they thought about how they might teach mathematics in the future (Wilson \& Thornton, 2006).

This paper extends the theoretical framework that shows how bibliotherapy can be used to describe cognitive and affective aspects of pre-service teacher reflection. It makes two significant and new contributions: it shows how bibliotherapy can enhance pre-service teachers' meta-affective capability (DeBellis \& Goldin, 1997); and it shows how bibliotherapy can enhance pre-service teachers' capacity to project themselves into their future role as teachers. 


\section{Literature Review}

In this review, we introduce the process of bibliotherapy and explain how it can assist teacher educators to better understand the emotional and cognitive responses of pre-service primary teachers in mathematics education subjects. We discuss the concepts of meta-affect and projective identity, explaining their connection to the process of bibliotherapy.

\section{Bibliotherapy}

Bibliotherapy is a technique which aims to assist individuals to overcome negative emotions related to a real-life problem through guided reading. It is "a process of dynamic interaction between the personality of the reader and literature - interaction which may be utilized for personality assessment, adjustment and growth” (Cornett \& Cornett, 1980, p. 8). The procedure is based on the active process of reading about the dilemmas of a third person, followed by individual or group discussion in a non-threatening environment (Aiex, 1996). Underlying the application of bibliotherapy is the assumption that reading is a dynamic process, in which the reader is an active participant and identifies with the protagonist in the story. When people read they interpret through the lens of their own experiences. As the reading involves a third person, the reader is removed from the situation and is able to experience the problem from an objective viewpoint. This interactive process has the capacity to "to heal and enthuse" (Martin 2002, p. 34).

Researchers in the field of bibliotherapy describe four stages: identification, catharsis, insight and universalization (Halstead, 1991; Hebert \& Furner, 1997). These stages of bibliotherapy can be summarized as:

Identification - the reader identifies with and relates to the protagonist. The reader recognizes herself and her situation in the readings. "Examining the behaviors and related motives of another individual can act as a transition into the exploration of one's own perceptions and actions” (Morawski, 1997, p. 247).

Catharsis - the reader becomes emotionally involved and releases pent-up emotions. Tension is released and this is accompanied by an "emotional feeling that lets the readers know they are not alone in facing their problems” (Hebert \& Furner, 1997, p. 168). Identification is thus more strongly established, and the reader is better positioned to profit from reviewing the feelings associated with the incidents that are recalled during the identification phase. 
Insight - this stage moves the emphasis to the reader. "Insight is the reader's application of the character's situation to her own life” (Halstead, 1991, p. 67).The reader envisages new ways of looking at the issues that they face (Hebert \& Furner, 1997)'learns through the experiences of the character and becomes aware that her problems might also be addressed or solved. Having achieved release from some of her emotional tension, she becomes more inclined to evaluate the reasons behind her attitudes and behaviors. The reader is positioned to deconstruct her past views, and the understanding that she gains from this process helps her to recognize that her current feelings are valid in the light of her past experiences.

Universalization - the recognition that we are not alone in having these problems, we “are in this together" (Slavson, 1950, quoted in Hebert \& Furner, 1997, p. 170). One of the reasons for using the technique of bibliotherapy is for an individual to come to the realization that she is not the only one who has the problem (Aiex, 1996).

The act of reading alone does not comprise the full process of bibliotherapy. Hebert and Furner (1997) stress that "successful bibliotherapy requires a meaningful follow-up discussion” (p. 169). Activities such as discussions and journal writing enable the reader to develop self-awareness, an enhanced self-concept and improved personal and social judgment. One of the benefits of sharing reflective writing is that students are exposed to a range of attitudes and experiences with which they can identify (Flores \& Brittain, 2003).

As Ambrose (2004) emphasizes, emotion-packed vivid experiences that leave a lasting impression are essential ingredients in stimulating affective changes in pre-service teachers. These experiences can be identified in the process of bibliotherapy discussed above. They are precisely the catalysts that stimulate catharsis. Insight and universalization, i.e. the cognitive elements of bibliotherapy, are contingent upon this emotional response.

The technique of bibliotherapy has been used to help high ability secondary students overcome mathematics anxiety (Furner \& Duffy, 2002; Hebert \& Furner, 1997), to assist children with learning disabilities (Forgan, 2002; McTague, 1998), to remediate children's social difficulties (Sullivan \& Strang, 2003) and in preparing pre-service teacher to teach students with emotional and behavioral disorders (Marlowe \& Maycock, 2000). Morawski (1997), using bibliotherapy in units about teaching reading and teaching students with special needs, concludes that it can be a stimulus for reflective practices in both pre-service and inservice teacher education. While this study did not use bibliotherapy as an interventionist technique it contributes to the growing application of bibliotherapy in education by showing its potential to help teacher educators better understand the emotional responses of preservice primary teachers to mathematics (for example, Wilson, 2012). 


\section{Affect, Meta-Affect and Mathematics}

I was so inhibited by my incomprehension that I did not dare to ask any questions. Mathematics classes became sheer terror and torture to me. Other subjects I found easy; and as, thanks to my good visual memory, I contrived for a long while to swindle my way through mathematics, I usually had good marks. But my fear of failure and my sense of smallness in the face of the vast world around me created in me not only a dislike but a kind of silent despair which completely ruined school for me. (Jung, 1977, p. 45)

Affective issues in the learning of mathematics have been the subject of significant research for many years (Schuck \& Grootenboer, 2004; Thompson, 1992). As Jung so vividly describes in his autobiographical account of his own schooling, failure in mathematics can have a powerful emotional impact that may extend far beyond the mathematics classroom. For potential teachers of mathematics this emotional impact becomes doubly significant, potentially affecting not only their current study but also their future teaching of mathematics and hence the attitudes of their future students.

Of particular significance in considering emotional aspects of pre-service primary teacher education is the phenomenon of mathematics anxiety (Haylock, 2001). Hembree's (1990) meta-analysis of research studies found that the level of mathematics anxiety of preservice elementary teachers was the highest of any major on university campuses. Trujillo and Hadfield (1999) trace the roots of mathematics anxiety in American pre-service primary teachers, and identify five principal factors: self-perceptions, school experiences relating to mathematics, teachers, family influences and mathematics test anxiety. These factors were strongly reflected in this study, in which many of the pre-service teachers expressed high levels of mathematics anxiety.

While it is important that pre-service teachers have positive experiences of mathematics in their teacher education courses, it may be equally important to heighten their awareness of affective issues and thus to enhance their meta-affective capability (DeBellis \& Goldin, 1997) Meta-affect concerns people's awareness of, and emotions about, their emotional states, and their way of monitoring and regulating emotion. For example, Goldin (2002) contrasts the young child's debilitating fear of the dark with the fear experienced on a roller-coaster which, providing the person feels safe, enhances the thrill of the ride. He claims that the different meta-affective states associated with fear arise from different cognitive beliefs and values. DeBellis and Goldin (2006) suggest that "the most important affective goals in mathematics are not to eliminate frustration, remove fear and anxiety or make mathematical activity consistently easy and fun. Rather they are to develop meta-affect where the emotional feelings about the emotions associated with impasse or difficulty are 
productive of learning and accomplishment” (p.137). We suggest that bibliotherapy empowers pre-service teachers to see personal anxiety about mathematics as positively influencing their capacity to teach more effectively. That is, pre-service teachers' emotions can be harnessed to contribute to the development of a positive projective identity.

\section{Projective Identity}

Gee (2003) examines the design of video games, looking particularly at what they show about effective learning. One of the design features of video games identified by Gee is the development of a strong "virtual identity", in which the game player projects her own values onto their virtual character, imbuing that character with her own values and desires. The player sees the character as their "project in the making", what she wants it to be and become. Gee suggests that projective identity creates ownership, and that "something magic happens" when learners take on a projective identity. They feel what it is like to have the capacity to be the sort of person they have created and built their character to be. This is a transformative experience, touching on cognitive and emotional elements as well as future actions. We suggest that this transformation is a critical aspect of pre-service teacher education in mathematics, and one that can be enhanced through the process of bibliotherapy.

Personal and professional transformation is a critical factor in teacher education, where intrapersonal awareness and growth need to become an integral part of the ongoing construction of knowledge and practice. In particular, teachers need to gain an understanding of their perceptions as well as the influence that these perceptions can have on their attitudes and actions in the educational setting (Morawski, 1997, pp. 255-6)

\section{Research Approach}

\section{The context}

The setting for this study was an elective unit Mathematics and Learning Difficulties at an Australian urban university. This unit, which supplemented compulsory units in mathematics content knowledge and pedagogy, focused specifically on difficulties schoolaged children experience in mathematics as a consequence of specific learning difficulties or of cultural and attitudinal factors. The emphasis of the unit was on students who struggle in the mainstream classroom rather than those with severe learning difficulties. The topics discussed during the unit included mathematics anxiety, mathematical understanding, the social context of the classroom, language factors, and ways of addressing students' individual needs. 
In the first workshop of the unit pre-service teachers were asked to describe a critical incident in their own school mathematics education that impacted on their image of themselves as learners of mathematics. This incident could have been positive or negative.

During each week of the unit, pre-service teachers were required to read articles that related to the experience of learning mathematics in a classroom, particularly for those students who find it difficult or suffer anxiety. These readings were chosen to give a broad overview of the difficulties that primary school students have in learning mathematics. They included readings about mathematics anxiety (Dossel, 1993), understanding in mathematics (Skemp, 1976), classroom interactions (Zevenbergen, 2000) and exclusion from school mathematics (Walkerdine, 1990). The readings focused on both psychological and sociocultural aspects of learning mathematics, and encouraged pre-service teachers to consider both the affective and the cognitive dimensions. We particularly chose readings that we felt were likely to provoke an emotional response.

Part of the assessment for the unit required students to maintain a reflective journal. In this journal they were encouraged not only to consider the implications of the readings for children in schools, but also to reflect on their own experience of school mathematics. Prompts were provided for their responses to the readings, including:

- Something I learned

- Something I felt reassured by

- Something that surprised me

- Something I disagreed with

- Something I would like to know more about

This was presented as an open-ended task and did not require every prompt to be addressed.

In the following workshop, the students then shared as much of their reflective writing as they wished in a small group of their choosing, and each group was provided with an opportunity to raise issues they felt were important with the whole group. As teachers of the unit we attempted to create a supportive and non-judgmental environment in which reflective writing could be shared, with meaningful follow-up discussion. This process of publicly sharing reflections is emphasized in the literature as an essential component of bibliotherapy (Hebert \& Furner, 1997).

\section{The pre-service teaching students}

Thirteen pre-service primary teachers (twelve females and one male) participated in the unit. They encompassed a range of academic years from the second year to the fourth year of their primary education degree. All had studied one unit of mathematics content, and 
had completed or were simultaneously completing one unit focusing on mathematics pedagogy. All had completed at least two three-week periods of professional teaching experience in primary schools. The pre-service teachers in the fourth year of their degree had completed a second unit of mathematics pedagogy and an eight-week teaching internship in addition to those completed by the second or third year pre-service teachers. Most of the students were studying the unit as part of an inclusive education major. They did not necessarily have negative feelings themselves about mathematics but they were particularly interested in school students who had cognitive or emotional difficulties in mathematics.

\section{Data collection and ethics}

The reflective journals, consisting of the critical incident report and the regular weekly responses to the readings, were the source of the data for this study. Those who agreed to participate in the study could choose to send additional reflections to a third party without the lecturer's knowledge, for the purposes of research only. They were aware that these additional reflections did not form part of the assessment for the unit and did not need to satisfy formal assessment requirements. A clear distinction between criteria used for formal assessment in the unit and the use of reflective writing as a research tool was made. All additional reflections that had been submitted were sealed until the unit was finished and formal assessment had been completed. Although sharing of reflections and in-class discussions were important elements in creating a supportive and non-judgmental environment, for ethical reasons they were not recorded and are not reported in this study.

This research design was examined by the university's ethics committee to ensure that results would not be skewed by pre-service teachers submitting spurious reflections purely in order to pass the unit.

All thirteen pre-service primary teachers agreed to participate in the research, however the researchers did not know this until after the unit assessment had been completed. Fictitious female names were assigned to all pre-service teachers to preserve anonymity.

\section{Data analysis}

After the completion of the unit, the critical incidents and journals were read and summarized independently by three researchers, who each identified common themes (Wilson \& Thornton, 2005). The themes identified by each of the researchers were compared and synthesized.

The study was designed to provide a snapshot of how the pre-service teachers felt about themselves as learners and potential teachers of mathematics at the start of the unit, and 
to examine how those feelings changed as the unit progressed. It was not designed to provide a rigorous pre and post unit comparison of their beliefs and self-efficacy, nor was it designed as a systematic analysis of beliefs or emotions based on pre-existing research. Rather, it was an interpretive study based on a small number of very rich written reflections.

\section{Results and Discussion}

\section{Themes emerging from the critical incidents}

The critical incidents provided a snapshot of how pre-service teachers felt when they started the unit (Wilson \& Thornton, 2005). The act of writing about these incidents in their own school mathematics evoked some intense memories. Although no specific direction was given when asking the pre-service teachers to write about a critical incident, they overwhelmingly chose to write about an experience in their own schooling that provoked negative rather than positive feelings towards mathematics.

Themes identified were: (1) the lasting influence of an individual teacher; (2) the cycle of fear failure and avoidance; (3) their self-image as a learner of mathematics; (4) their perceptions of the nature of mathematics; and, less commonly, (5) the influence of parents, (Wilson \& Thornton, 2008). There are parallels between the themes identified here and those in the literature relating to mathematical autobiographies of pre-service teachers (Sliva \& Roddick, 2001; Ellsworth \& Buss, 2000).

The critical incidents thus provided a snapshot of the pre-service teachers' emotions and beliefs about the causes of those emotions at the commencement of the unit. This awareness of emotions, their causes and their impact is a critical aspect in developing metaaffective capabilites (DeBellis \& Goldin, 2006). Like the young child's fear of the dark (Goldin, 2002), for the most part these emotions had proved debilitating during the preservice teachers' own school experiences.

We now describe how the process of reading and reflecting during the unit, described by the stages of bibliotherapy, provided a means by which these emotions, like the positive fear of a roller coaster, became productive in enabling the pre-service teachers to see themselves as potentially more effective teachers of mathematics.

\section{Bibliotherapy in This Study}

The on-going reflective process of journaling provided data with which to examine how the pre-service teachers' attitudes changed during the unit in response to the readings. In particular it enabled us to use bibliotherapy as a framework to understand this change 
process. The readings in the unit provided a mirror in which pre-service teachers could see themselves and their school experiences, and a lens through which they could construct themselves as potentially enthusiastic and effective future teachers of mathematics. The journal entries provided evidence that students did indeed experience a powerful emotional response to the readings, reflected deeply on their own experiences in the light of the readings and engaged in all four stages described in the literature relating to bibliotherapy (Aiex, 1996).

\section{Stage 1: Identification}

Several pre-service teachers identified closely with an article by Dossel (1993) which describes the possible causes of mathematics anxiety among school students. Barbara saw herself in their situation and could recognize the defensive barriers she had erected during her own schooling.

The article by Steve Dossel (1993) presented issues that I was able to relate to personally... I related deeply to the 'unconscious defends itself' statement by Walkerdine, (1990). (Barbara)

Skemp's (1976) discussion of relational and instrumental understanding also provoked a strong reaction among the pre-service teachers. They identified the instrumental nature of their own schooling and saw that it had been debilitating for them.

This is how I viewed maths, as long as I knew the set of rules and applied them appropriately then I didn't really need to know why. To me maths was all about getting the right answer. (Mandy)

Despite three years of studying mathematics and mathematics education subjects at university, it was the experience of focusing on students with learning difficulties that prompted Mandy and Barbara to explicitly connect the cognitive components of their preservice teacher education with their own experiences as learners of mathematics in school. The identification stage of bibliotherapy thus represents the beginnings of an enhanced metaaffective awareness.

\section{Stage 2: Catharsis}

Through their reading of the articles the pre-service teachers became emotionally involved and shared and released pent-up emotion. Several reflected on their own mathematics anxiety having read about children’s mathematics anxiety in Dossel (1993).

I am currently studying maths ....and let me tell you the fear that has risen in me is nasty. Even though these subjects are not about the actual content of maths the very fact they are to do with maths terrifies me. (Felicity)

There seems to be an overwhelming fear of failure from everyone - parents, teachers, society - 'You fail in math, you fail in life' mentality. (Gail) 
These are classic examples of students responding emotionally and connecting the readings with their past experiences. The strength of these responses, as shown by Felicity's use of words such as 'nasty' and phrases such as 'let me tell you', indicates a release of emotion that is essential if people are to begin to recognize the causes of their feelings and, as with the fear of the roller coaster, to use these feelings productively.

\section{Stage 3: Insight}

Through reading articles focused on the reasons school students struggle with mathematics, the pre-service teachers became more aware that their problems were not necessarily of their own making and could thus be addressed or solved. In some cases they recognized that this was related to the nature of the mathematics studied and the type of understanding they felt was valued in their schooling.

Instrumental and relational learning (Skemp, 1976) was a bit of a mind blower for me and funnily enough gave me a little more confidence within myself, that it was the way I was taught that has made me mathematically challenged not my actual intelligence. (Felicity)

Some reflections showed progress in pre-service teachers' perceptions of themselves as learners of mathematics. These included development of a deeper understanding of what it means to learn mathematics, and awareness that there are alternatives to the approaches that they experienced. Jenny, reflecting on a reading about excellent mathematics teaching from Reys, Lindquist, Lambdin, Smith and Suydam (2002) expressed her frustration very concisely.

Basically I feel a bit cheated - like I got a second rate education. (Jenny)

These reflections contain a strong cognitive component, in that they show understanding of how emotions have arisen. As emphasized by DeBellis and Goldin (2006), this cognitive element is critical in developing meta-affective capability, as it is knowledge that enables us to monitor and regulate our emotions. However, the pre-service teachers' use of emotionally charged words such as "mind blower", "cheated" and "second rate" also demonstrate the impact of the cathartic experience. As described in bibliotherapy, insight is deepened when it is accompanied by catharsis.

\section{Stage 4: Universalisation}

Using their reflections on the readings and through the sharing of their experiences pre-service teachers were able to connect with each other and find that they were not alone in their feelings and experiences. The recognition that others have the same issues and one is not alone (Rizza, 1997) was particularly evident during the shared reflections. 
The biggest thing I think I have learned this week was that I am really not alone in this anxiety there are lots of my peers and children still there with me. (Felicity)

A conviction that one is alone in one's feelings of anxiety and the overwhelming desire to conceal that emotion makes it almost impossible to discuss and resolve these feelings. Through the sharing of responses to readings in the privacy of a small group, followed by a more public sharing as they felt able, the pre-service teachers' feelings of aloneness were reduced. Felicity's use of the term” still there with me” shows her willingness to admit her anxiety and expose her fears. Her capacity to express solidarity with students who find mathematics difficult stems from the identification, catharsis and insight described by bibliotherapy. The feelings of aloneness experienced by the young child afraid of the dark are in stark contrast to the shared fear and accompanying exhilaration experienced by the riders of a roller coaster, and to the sense of solidarity promoted by the discussions of the readings.

\section{Stage 5: Projection}

The pre-service teachers' added insight into their own circumstances was followed by a consideration of what this could mean for the future. While we would expect pre-service teachers to imagine themselves as future teachers, it was the vehemence with which they rejected the way in which they felt they had been taught, accompanied by the vividness with which they described the type of teacher they wanted to be that surprised us when we read their reflections. We observed this not only among those nearing the end of their study, but also in the reflections of those pre-service teachers who were only in the second year of their course. The prevalence and strength of this aspect of their reflections was so striking that we identified it as worthy of description in its own right. We term this fifth stage of the bibliotherapy process “projection” (Wilson \& Thornton, 2008).

I can only hope that at the end of this semester I can turn this around and actually make a difference to another child so that they don't experience what I have...I feel more determined in teaching maths well, so students don't suffer through maths as I did. (Felicity)

There is no place for the methods of my past in classrooms of today if I wish to stop the cyclical nature of instrumental mathematics teaching experienced to date. (Barbara)

In several cases during the eight weeks of the journal reflections the focus of the preservice teachers' comments moved from reflections about how inadequate they felt to the reassurance they felt when faced with research that concluded that the best teachers were not always those who had performed best in mathematics at school. 
It gives me great comfort to know that although I may not graduate at the top of the mathematics class, this will have no lasting bearing on my ability to teach it (Jenny)

As the semester progressed extensive sections of some of the pre-service teachers' journals were devoted to a consideration of the effects of the readings on their intended teaching practices. The comments about teaching fell into several categories - their views of mathematics itself, characteristics of good teachers of mathematics, and their aim for their own teaching to be substantially different from the way that they were taught. Some of the comments addressed specific issues such as the need to ensure that their students see purpose and make connections in their mathematics learning. Others showed detailed analysis of applications taken from particular readings, and descriptions of learning tools that they intended to incorporate into their classrooms. Thus rather than expressing inadequacy, as in their earlier reflections, their later reflections contained practical thoughts and strategies to make them more effective teachers

In particular, the insights developed through the readings convinced the pre-service teachers of the need to achieve positive attitudes in their classrooms. Their comments reflected a determination that negative learning experiences would not be transferred to their students and continue a cycle of negative attitudes, beliefs and feelings about mathematics. More powerfully, some pre-service teachers saw their own past fears and inadequacies as learners of mathematics as being positive factors in helping them to become more effective teachers. The identification, catharsis, insight and universalization described in the bibliotherapy process were instrumental in enabling the creation of a projective identity that was in stark contrast to the timidity with which they had previously viewed themselves as learners and potential teachers of mathematics. Like the game players described by Gee (2003), the pre-service teachers underwent a transformative experience, feeling what it was like to have the capacity to be the sort of teacher they did not themselves have as a learner. Jenny, in particular, captured the dual emotional and cognitive aspects of the projection stage of bibliotherapy.

This also leads me to my second thought that, for those teachers, who like me, have never believed maths to be their "thing", there is the distinct possibility that our desire not to let students suffer our fate and to improve on our own childhood experiences in classrooms could well be the factor that makes us more effective teachers. We are more open to the need for reflective teaching and professional development, and more willing to look for alternate explanations and examples. (Jenny, emphasis added) 


\section{Conclusion and Implications}

The five stages of bibliotherapy described above explain how meta-affective change might take place. We suggest that each is critical in enabling pre-service teachers to develop greater awareness of their own emotions about mathematics, and in developing the capacity to monitor and regulate these emotions. Goldin (2002) claims that meta-affect is the most important aspect of affect. He states (p.71) that "it will be important to provide experiences that are sufficiently rich, varied, and powerful in their emotional content to foster the students' construction of new meta-affect. This is a difficult challenge indeed.” As evidenced by the transformation in the pre-service teachers' meta-affect described above, we claim that the stages of bibliotherapy may provide just such a set of experiences, and hence go some way towards meeting that challenge.

Not only were the pre-service teachers more enthused about their potential as teachers of mathematics, but their concept of themselves as learners of mathematics was sufficiently healed that they were willing to confront mathematical concepts they had not understood in their schooling. As several asked after one session: “Can you explain trigonometry to me?” In asking for an explanation of trigonometry, the pre-service teachers were not merely asking for mathematical content. Rather, they were exhibiting a powerful meta-affective transformation by acknowledging that their past lack of understanding had not been because of an inherent mathematical inability, but that, given a more appropriate explanation, they would be able to understand concepts they had once found difficult. The meta-affective capability gained through reading and reflection, and described in the stages of bibliotherapy, made them open to new ideas and keen to explore new challenges.

In this study the stages of bibliotherapy were not linear, sequential or something that only happens once. It was a cyclic process, with each reading provoking a range of cognitive and emotional responses that we have described using the stages of bibliotherapy, and that contributed to meta-affective capability. The intensity and nature of the responses were different for different participants. However, as the unit progressed the balance of the preservice teachers' responses moved towards the development of greater insight, and ultimately towards robust and healthy projection into the situation of teaching.

Understanding the process of bibliotherapy, and providing stimulus and space for preservice teachers to read and respond to the difficulties faced by children at school may thus enable teacher educators to assist all pre-service teachers to develop a more robust projective identity with healthy cognitive and emotional components. 


\section{References}

Aiex, N. (1996). Bibliotherapy. Available on line at http://www.ldonline.org/ld_store/bibliotherapy/eric_digest82.html

Ambrose, R. (2004). Initiating change in prospective elementary school teachers' orientations to mathematics teaching by building on beliefs. Journal of Mathematics Teacher Education, 7, 91-119.

Buerk, D. (1982). An experience with some able women who avoid mathematics. For the Learning of Mathematics, 3(2), 19-24.

Cornett, C., \& Cornett, C. (1980). Bibliotherapy: The right book at the right time. Bloomington, Ind.: Phi Delta Kappa Educational Foundation.

DeBellis, V., \& Goldin, G. (1997). The affective domain in mathematical problem-solving. In E. Pekhonen (Ed.) Proceedings of the 21st Annual Meeting of the International group for the Psychology of Mathematics Education (Vol 2, pp. 209-216). Lahti, Finland: Univ. of Helsinki,

DeBellis, V. ,\& Goldin, G. (2006). Affect and meta-affect in mathematical problem solving: a representational perspective. Educational Studies in Mathematics, 63(2), 131-147

Dossel, S. (1993). Maths anxiety. Australian Mathematics Teacher, 49(1), 4-8.

Ellsworth, J., \& Buss, A. (2000). Autobiographical stories from preservice elementary mathematics and science students: Implications for K-16 teaching. School Science and Mathematics, 100(7), 355-364.

Flores, A., \& Brittain, C. (2003).Writing to reflect in a mathematical methods course. Teaching Children Mathematics, 10(2), 112-118.

Forgan, J. (2002). Using bibliotherapy to teach problem solving. Intervention in School \& Clinic, 38(2), 75-82.

Furner, J., \& Duffy, M. (2002). Equity for all students in the new millennium: Disabling math anxiety. Intervention in School and Clinic, 38(2), 67-75.

Furner, J. \& Gonzalez-DeHass, A. (2011). How do students' mastery and performance goals relate to math anxiety? Eurasian Journal Of Mathematics, Science \& Technology Education, 7(4), 227-242.

Gee, J. P. (2003). What video games have to teach us about literacy and learning. New York: Palgrave Macmillan.

Goldin, G. (2002). Affect, meta-affect and mathematical belief structures. In G. Leder, E. Pehkonen\& G. Törner (Eds.), Beliefs: A hidden variable in mathematics education (pp. 59-72). Dordrecht: Kluwer.

Halstead, J. (1991). Guiding gifted readers. Melbourne: Hawker Brownlow Education.

Haylock, D. (2001). Mathematics explained for primary teachers. London: Paul Chapman.

Hebert, T., \& Furner, J. (1997). Helping high ability students overcome maths anxiety through bibliotherapy. Journal of Secondary Gifted Education, 8(4), 164-179.

Hembree, R. (1990). The nature, effects and relief of mathematics anxiety. Journal for Research in Mathematics Education, 21(1), 33-46.

Hendricks, C., Hendricks, J. \& Cochran, L (1999). Using literacy conversations for healing: The significant conversationalists. American Reading Forum Online Yearbook Vol XIX.http://americanreadingforum.org/yearbook/yearbooks/99_yearbook/pdf/8_hendricks 99.pdf

Jung, C. (1977). Memories, dreams, reflections (R. Winston \& C. Winston, Trans.). Great Britain: Collins Fount Paperbacks.

Marlowe, M.,\&Maycock, G. (2000). Phenomenology of bibliotherapy in modifying teacher punitiveness. Journal of Genetic Psychology, 161(3), 325-336

Martin, L. (2002). Using books to heal and enthuse gifted students. Gifted,123, 34-35. 
McTague, K. (1998). Children's literature: Bibliotherapy and learning problems. Unpublished Masters' Dissertation. Kean University of New Jersey.

Morawski, C. (1997). A role for bibliotherapy in teacher education. Reading Horizons, 37(3), 243-259.

Morawski, C., \& Gilbert, J. (2000). Developmental interactive bibliotherapy. College Teaching, 48(3), 108-114.

Pajares, M. (1992) Teachers' beliefs and education research: Cleaning up a messy construct. Review of Educational Research,62(3) 301-332.

Reys, R., Lindquist, M., Lambdin, D., Smith, N. \& Suydam, M. (2002). Helping Children Learn Mathematics. New York: John Wiley \& Sons Inc.

Rizza, M. (1997). A parent's guide to helping children: Using bibliotherapy at home. http://www.gifted.uconn.edu/nrcgt/newsletter/winter97/wintr972.html

Schuck, S., \& Grootenboer, P. (2004). Affective issues in mathematics education. In B. Perry, G. Anthony \& C. Diezmann (Eds.), Research in mathematics education in Australasia 2000-2003 (pp. 53-74).Flaxton, Qld: Post Pressed.

Skemp, R. (1976). Relational understanding and instrumental understanding. Mathematics Teaching, 77, 20-26.

Sliva, J., \& Roddick, C. (2001). Mathematicsautobiographies: A window into beliefs, values, and past mathematics experiences of preservice teachers. Academic Exchange Quarterly, 5(2), 101-107.

Sullivan, A., \& Strang, H. (2003). Bibliotherapy in the classroom: Using literature to promote the development of emotional intelligence. Childhood Education, 79(2), 74-80.

Thompson, A. (1992). Teachers' beliefs and conceptions: A synthesis of the research. In D. Grouws (Ed.), Handbook of research on mathematics teaching and learning (pp. 127146). New York: Macmillan.

Trujillo, K., \& Hadfield, O. (1999).Tracing the roots of mathematics anxiety through in-depth interviews with pre-service elementary teachers. College Student Journal, 33(2), 219232.

Walkerdine, V. (1990). Difference, cognition and mathematics education. For the Learning of Mathematics, 10(3), 51-56.

Wilson, S. (2012). Bibliotherapy: a powerful tool to address mathematics anxiety in preservice primary teachers. In A. L. White \& U. H.Cheah (Eds.), Transforming School Mathematics Education In the 21st Century. (pp. 317 - 329). Penang: SEAMO RECSAM.

Wilson, S., \& Thornton, S. (2005). The year in which my love of maths changed: Pre-service primary teachers' self-image as mathematicians. In M. Coupland, J. Anderson \& T. Spencer (Eds.), Making Mathematics Vital: Proceedings of the 20th biennial conference of the Australian Association of Mathematics Teachers(pp.268-274). AAMT: Adelaide

Wilson, S. \& Thornton, S (2006). To heal and enthuse: Developmental bibliotherapy and preservice primary teachers' reflections on learning and teaching mathematics. In P. Grootenboer, R. Zevenbergen \& M. Chinnappan (Eds.), Identities, Cultures and Learning Spaces: Proceedings of the 29th annual conference of the Mathematics Education Research Group of Australasia (pp. 36-44). AAMT: Adelaide.

Wilson, S. \& Thornton, S. (2008) “The factor that makes us more effective teachers”: Two pre-service primary teachers' experience of bibliotherapy. Mathematics Teacher Education and Development, 9, 21-35

Zevenbergen, R. (2000). "Cracking the code" of mathematics classrooms: School success as a function of linguistic, social, and cultural background. In J. Boaler (Ed.), Multiple perspectives on mathematics teaching and learning (pp. 201-224). Westport, CT: Ablex. 